\title{
11
}

\section{MEMORY NARRATIONS AS A SOURCE FOR HISTORICAL ETHNOGRAPHY AND THE SENSORIAL-AFFECTIVE EXPERIENCE OF MIGRATION}

\author{
Marija Dalbello and Catherine McGowan
}

\section{Introduction}

Ellis Island in the Port of New York, an immigrant station during the Great Migration from Europe to America at the start of the twentieth century, has been the main symbol of a shared migration experience of European Americans for nearly half a century, signifying and sentimentalizing the grit of immigrant life, and shaping the image of America as "a nation of immigrants", a phrase originating from the title of John F. Kennedy's book published in 1964. That particular structure of feeling has been at the centre of the popular politics of memory that discursively constructed transatlantic migration in public culture. We engaged that discourse empirically by developing an approach for "aggregative" reading across a corpus of interviews from the Ellis Island Oral History $(\mathrm{EIOH})$ collection and in two case studies. We focused on the sensorial-affective dimensions of migration, meaning those that represented the physiological, sensing, or synesthetic imagining of migration in the vernacular narratives of the EIOH collection. Oral history storytelling involves sensorial interpretation of experience in which individuals rely on kinaesthetic, visual, sonic, or olfactory representation of particularly "magical moments" that become devices for resolving complex timeframes of migration or an emotion.

Our test corpus consisted of the Central and Southern European oral history interviews documenting the perspectives of the participants in that historical migration. These pre-elicited oral history interviews document and mediate a historical sensorium of the Great Migration, so far an untapped archive for understanding the sensorial and affective dimensions of migration of particular groups and individuals. Studying migration from the point of view of senses and sensory experiences or material culture, as exemplified in the studies of ethnic food, is not unknown in migration scholarship. Studying an entire historical migration sensorium using a vast body of oral histories is a new and ground-breaking twist in ethnographic research. We define historical 
ethnography as a tool for historical explanation drawing from the traces of the past, while considering how the relationship between the past and these traces is mediated through oral histories as documents and how the description of experience in the first person reflexively engages the historian-ethnographer's position. In our overall interpretive approach, we draw on and combine the methodological imperatives of history (documentation) and ethnography (reflexivity). We reflect on the methodology for reading life histories combining a macro- (across the corpus) with micro-analytic approaches (of case studies) in order to demonstrate their complementarity and value in historical ethnography.

\section{Reading across a corpus of interviews}

\section{Ellis Island oral histories: general remarks}

The Ellis Island Oral History (EIOH) collection contains 1,893 oral histories by immigrants and some United States government agency employees. The analysis draws interviews from Austria-Hungary, Croatia, and Italy. These Central and South European cases belong to a particular historical sensorium of migration from areas of Europe that are comparable and contemporaneous with the highest emigration and immigration cohort of the Great Migration. Creating the corpus for analysis required web scraping and manual verification and inventory of downloaded files. We extracted demographic information in that subset of the EIOH archive using metadata from each record as well as analysis of transcripts, and sound recordings. The most complete interviews in the archive had audio files with transcripts, passenger information files, ship images, and extracts from ship manifests. We created a summary table that recorded completeness of files in our corpus.

TABLE 11.1 Summary of the record completeness and file inventory for the corpus

\begin{tabular}{|c|c|c|c|c|c|c|c|}
\hline \multirow[t]{2}{*}{ Country } & \multirow[t]{2}{*}{ Records } & \multicolumn{6}{|c|}{ Type of recording } \\
\hline & & Audio* & Transcript $\star \star *$ & $\begin{array}{l}\text { Audio } \\
\text { Only }\end{array}$ & $\begin{array}{l}\text { Transcript } \\
\text { Only }\end{array}$ & $\begin{array}{l}\text { Audio and } \\
\text { Transcript } \star \star \star\end{array}$ & $\begin{array}{l}\text { No } \\
\text { Audio or } \\
\text { Tran- } \\
\text { script }\end{array}$ \\
\hline $\begin{array}{l}\text { Austria- } \\
\text { Hungary }\end{array}$ & 18 & 11 & 11 & 1 & 1 & 10 & 6 \\
\hline Croatia & 11 & 2 & 0 & 2 & 0 & 0 & 9 \\
\hline Italy & 263 & 166 & 187 & 23 & 44 & 143 & 53 \\
\hline Total & 292 & 179 & 198 & 26 & 45 & 153 & 68 \\
\hline
\end{tabular}

NOTES: One passenger from Croatia group and six passengers from Italy are listed twice in the Ellis Island Oral History Project because they were listed both under their maiden and married names for the same interview.

$\star$ Audio only as well as audio and transcripts of these interviews are available.

$\star \star$ Transcript only as well as audio and transcripts of the interviews are available.

$\star \star \star$ Audio recording is available and there is a transcript of the interviews. 
The transcripts allowed for the identification of additional dimensions that were also recorded in spreadsheets including Other Modes of Travel; Passenger Record; presence of Audio Filename; Transcript Filename; as well as Interview Date 1; Interview Date 2; whether it was a Joint Interview; Interview Partner and the Immigration Date; Immigration Age; Birthdate; whether the migrant made Multiple Trips and if so, Trip Date 1, Trip Date 2, Trip Date 3; Special Notes recorded supplemental information. The features of the cases included in our analysis are presented in Appendix 11.1.

Because oral histories represent a wide-ranging archive of migration, the reconstruction of a historical sensorium of the Great Migration required further "semantic" reduction in order to understand the EIOH archive in terms of migration periods represented and to identify cases corresponding to a particular "generational cohort" and "migration sensorium". The generational cohort was identified by age at which they immigrated and time of emigration/immigration as well as the age when they recorded their life histories. The migration experiences of children and adults may be remembered differently because they belong to a particular historical ecology that defined their sensorium. The elders' memories "from a child's perspective" will result in narrated experiences that reveal "minor details and things in their physical environment that adults do not pay attention to" and retrospective reminiscence of childhood experience that results in a mixture between children's and adults' perspectives, the former re-interpreted "within the framework of later and present experiences and knowledge" (Koskinen-Koivisto and Seitsonen 2019, 25). Understanding the demographic composition of those interviewed addressed the methodological questions of "whose sensorium" is represented in the archive and pre-elicited interviews as useful historical evidence. In this corpus, the memories of youth and childhood "are recounted through an adult filter" (Laakkonen 2011, 304). While the materialized narrated memories carry the experience of multiple sites of memory (Kuusisto-Arponen and Savolainen 2016, 60-61), the individual experiences are "engrained in the body" as "bodily remembering” (Povrzanović Frykman 2016, 82, 84).

\section{Migration cohorts and generations in the migration sensorium}

The cohorts in the migration waves were inferred from the dates of immigration embedded in the transcript files and the metadata. Two-thirds of the interviews or 198 out of 292 had that information. The recorded immigration experience shown in Table 11.2 ranges from 1894 to 1964, with majority of the cases situated in the first quarter of the twentieth century.

Most of the interviewees immigrated as children and young adults (Table 11.3), which was relevant for the formation of the migrants' transnational experience and to understand the sensorium within their life histories. Many of them were accompanying larger family groups and were the only surviving members to recollect the migration sensorium. And, most of them were women. 


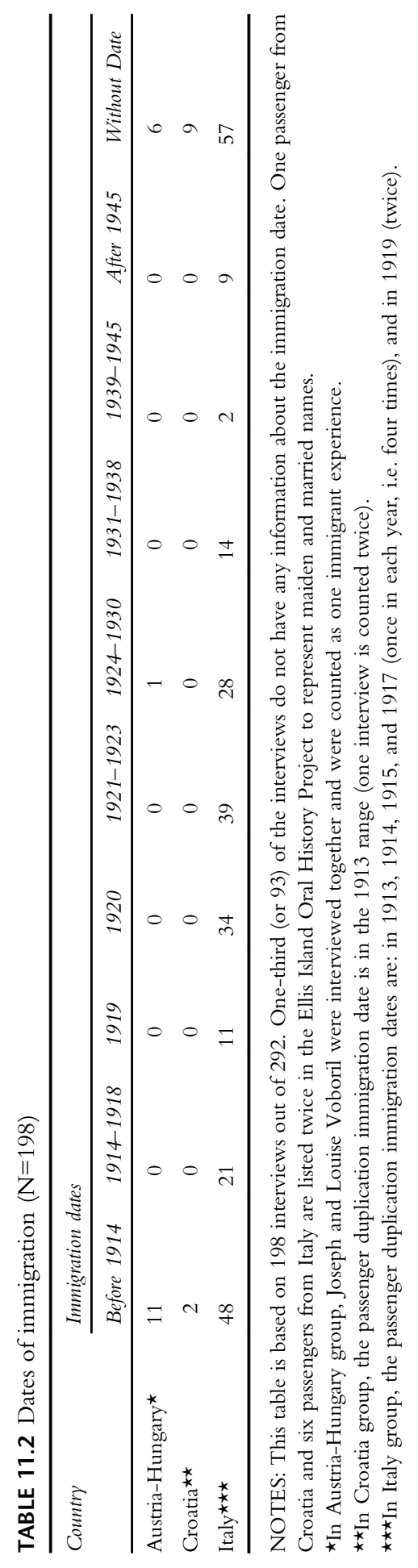


TABLE 11.3 Age at time of immigration as reported in the interviews

\begin{tabular}{llcccccc}
\hline Country & \multicolumn{7}{l}{ Age at immigration } \\
\cline { 2 - 8 } & $>2$ & $2-4$ & $5-9$ & $10-15$ & $16-19$ & $20<$ & Unknown \\
\hline Austria-Hungary & 0 & 0 & 4 & 4 & 2 & 1 & 7 \\
Croatia & 0 & 0 & 2 & 0 & 0 & 0 & 9 \\
Italy & 2 & 18 & 67 & 56 & 35 & 26 & 59 \\
Total & 2 & 18 & 73 & 60 & 37 & 27 & 75 \\
\hline
\end{tabular}

NOTES: When the immigration date is given, age could be inferred from the interviews and the metadata accompanying each record. One passenger from Croatia and six passengers from Italy have been listed twice in the Ellis Island Oral History Project to represent maiden and married names.

The sensoria represented within their recorded interviews are life spanning rather than migration eventfocused, which is important from the methodological perspective. This is due to how interviews were designed - to elicit and privilege certain types of memories (Varricchio 2011).

\section{Selecting the cases for analysis}

The life histories situated participants by age, story, generation, and the particular migration wave. The dates of recording, ranging from 1970s until 1990s, were defining this archive as well as the age, cognitive abilities of the interviewees, and the life span they reflected when interviews were collected. At the time of writing, there is little likelihood that any of the project participants is still living.

The Austria-Hungary interviews were collected in the earliest period of the project - in the 1970s and 1980s - when most of the participants were 70 to 90 years old, based on their birth dates, which ranged from 1881 to 1907. Half of them immigrated at the age of ten (five of 11 cases) and two individuals were 19 and 30 years old. The generational structure of Italy interviews points to immigration dates from 1894 to 1929 (based on 166 interviews with transcripts out of 263), also interviewed in their late 80s and 90s. (For a third of the Italian records missing information about the age at the time of immigration, some inferences could be made from the immigration date.) Their age at the time of migration was under 16; birth dates between 1888 and 1910. Given that most of Italian oral histories were collected in the early to mid-1990s, with sporadic inclusion of interviews from the 1970s and 1980s, they show a similar distribution in time of migration, age, and demographic features relevant for this analysis. The only case from the Croatia group was interviewed when she was 88 years old; she immigrated in 1913 at the age of six. We focused on 73 cases from the Italy corpus with 1919 as cut off immigration date. Italy, AustriaHungary and Croatia groups were situated in the migration wave occurring before and during World War I that affected all of these geographical areas. The participants in the oral history interviews were positioned along a comparable generational cohort of the same migration wave and the migration experiences of Central and South Europeans. The analysis encompassed 84 interviews: Austria-Hungary (10); Croatia (1); Italy (73). 


\section{Coding the sensorium of the Great Migration}

The coding of entities and sensory events and statements that fall within the phenomenological experiences through the senses (seeing, taste, touch, temperature, smell, and sound) and the complex multisensory-affective themes ("the sensorium" of a historical experience) were coded in the audio and text files using an open source PDF reader Skim, developed as the tool for this project and Avid Pro Tools for marking timestamps and extract coded segments. The resulting sensorial modalities shown in Table 11.4 include descriptions and incidence shared across the cases.

Visual sense or sight includes descriptive instances or imagined scenes prompting visual representation by the interviewers who were focusing on scenes of arrival. Several immigrants commented on the absence of now emblematic city skyline and scarcity of tall buildings or the sight of the lights running the length of the bridges or waiting to see the expected sight of the Statue of Liberty (as if spoken about or seen in a picture). One immigrant described the scene of separation; others would describe the homes they left, in visual imagery - for example, as made of stone or wood logs. Sound, while rarely mentioned, is tied to singing or voices of people and shouting, sound of horns, specific musical instruments, music, or musicians. The cheering and shouting on arrival to the Port of New York is noted in some interviews. The descriptions of the urban environment and its sounds are limited. (Some of the interviewees continued to travel to their new homes beyond the confines of the city and their experience of the city was fleeting.) Touch includes instances of a stranger teaching the immigrant how to wash her hands and fingernails in a manner that evokes the sense of touch; other codes mention kissing or embrace; or, the feeling of objects (such as the velvet couch in the second-class cabin). The synesthetic memories of taste included a complex multi-sensory experience of food - when remembering its preparation and reflecting on what was ordinary and common or what was novel. They reflected on what they ate on board of the ships and on the memories of new foods once they arrived to America or remembered foods in nostalgic terms. The subthemes within memories of food on the ships included bread, which they had made and brought with them or bread provided on board. The familiarity of rye or other dark-grain bread would be contrasted with white bread. In other examples, they would remember winemaking, the butchering of meat according to traditional methods, or picking their own fruits from the garden contrasted with store-bought fruits. The memories of new foods associated with the arrival to America included bananas, which were noted a few times as a new and exotic food. One passenger was particularly fascinated by soda and another amazed by the cheapness of apple pie at Ellis Island. Mary Thome shares about being able to "taste and smell the good gingerbread squares." Smell occurs in the context of food memories.

The National Park Service (NPS) interviewers worked with pre-existing templates aimed at the elicitation of particular memories of the steerage experience, Ellis Island inspections, and experiences at school. The incidence of shared 


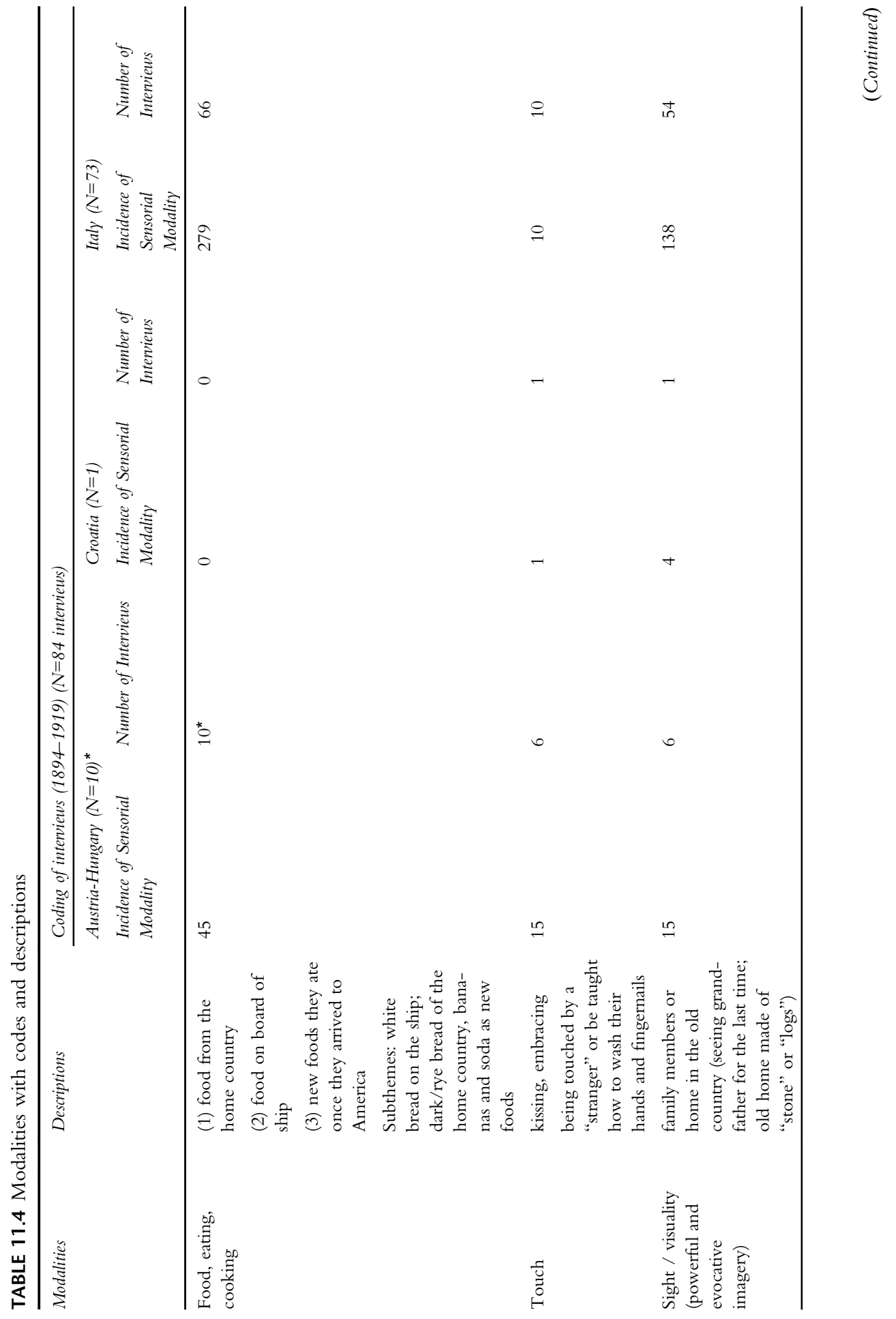




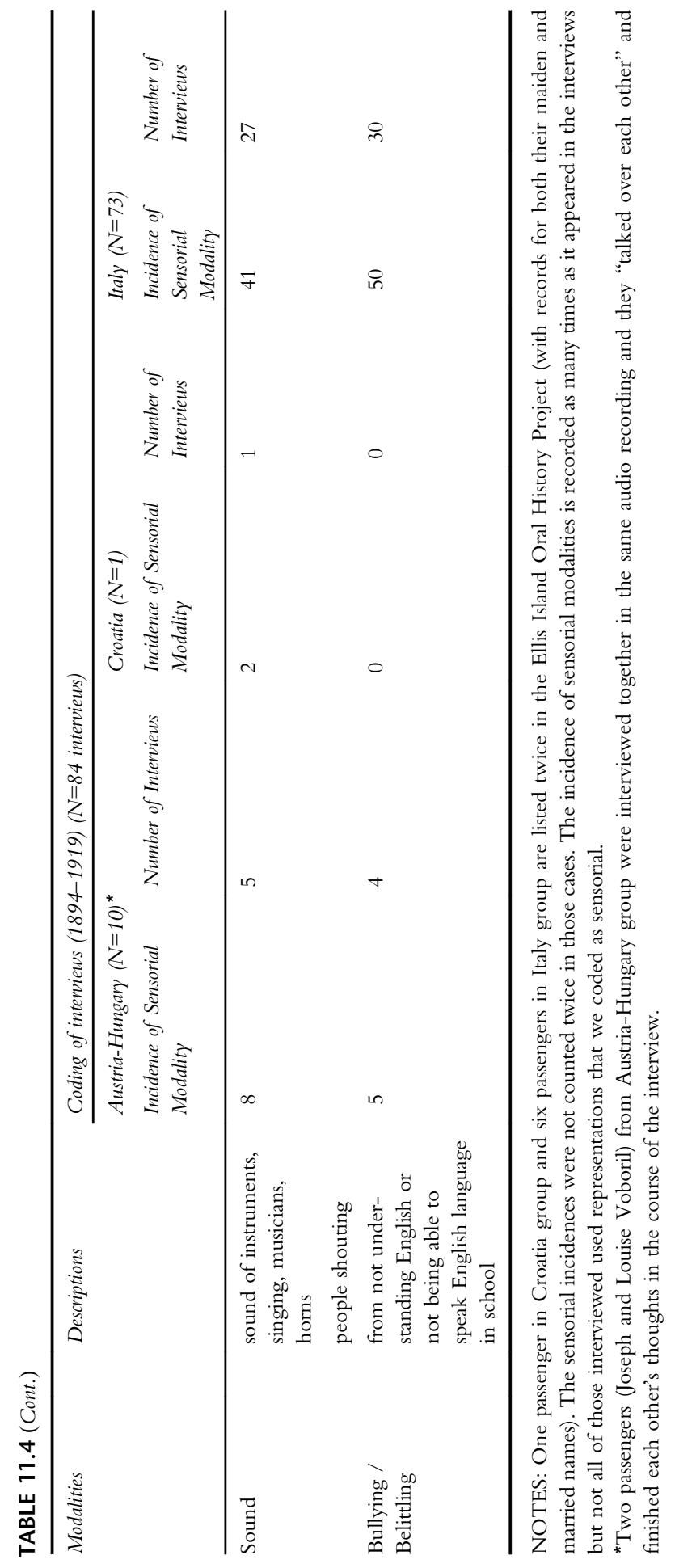


sensory themes across this corpus and the high frequency of "food" or the presence of "bullying" theme may have resulted from leading, consistent, and deliberate questions posed by the interviewers, such as "were you called greenhorn" or "And what was it like being, you know, not having the language and going to school" or "Well, how was school different in New York compared with the school you'd been in Italy?" These questions were assuming difficulty of assimilation due to language barriers or seeking a story of bullying. Mario Varricchio discusses the ideological impact of this interview guide and its role in constructing the archive to support the celebratory discourse of America as a nation of immigrants (2011). The interviewers' interventions often created confusion or forced breakdowns in the oral histories. For example, the Statue of Liberty was the leading sighting image that the interviewers insisted on: "What did you feel when you first saw the Statue of Liberty?" In some instances, the interviewees themselves closed that discussion by offering a negative response. Other respondents resisted in different ways. Their tactical evasions, including meaningful digressions, are discussed in the micro reading sections in this chapter. The invitation at the close of the interview, typically in the form of questions such as how do you feel about the decision to come to the US or looking back on your life, what are you most proud of - versions of the interview question, "Are you happy you came to America?" (Varricchio 2011, 28) elicited free-association and storytelling. The questions offered space for reflection outside of the interview protocol and often situated the narrations within interviewees' affective-sensorial context.

In the emerging migration sensorium that was shared, there is a high incidence of food and touch memories, and the powerful, evocative imagery that they recalled and described visually. Touch memories often follow a handful of themes such as clothing, straw beds, itching from bedbugs on the boat, waking to the feeling of urine falling on them from the child in the bunk above, physical touch during the Ellis Island inspection process. Next, two themes are presented in depth: visual sense (sight) modality, which has a high incidence across the corpus, and a complex affective-sensory theme of "bullying". Both of these themes are tied to the structuring of the interview questions, the effect critiqued by Mario Varricchio (2011) but nevertheless represent the dominant dimensions of the sensorium based on the "aggregative" reading of the corpus. The micro-readings address complementary acoustemological dimensions.

\section{Modalities of the migration sensorium: aggegrative analysis and interpretation}

\section{Visual sense (sight) modality}

The incidences of looking, seeing and visual metaphors mentioned in the interviews are exemplified by Rozia Frankel's statement that Ellis Island and the New York City bridges look "like a string of pearls with the lights on". Anna Vislocky describes the Statue of liberty looming "like a monster". Mary Thome recalls scenes in the inspection station, when immigrants adjusted their appearance to look 
healthier and elude or trick the "scopic regime" of medical inspections that aimed to control how they would appear or be seen (Jay 1994, 149; Rose 2016, 3). Stephen Houbrick associates the (colourful) plumed hats of the gendarmes harassing his mother and the dark clothes of the immigrants:

Everybody wore black clothes, black shawls and the men had the fedoras on. All dark clothes, I don't know why they wore dark clothes in Europe like that but that's what we come over with. It was the cheapest maybe.

In the interview by Andrew Lichanec, his departure is visually constructed: "looking through the window and I saw my grandfather standing under a tree until I got out of sight". This is a bridging afterimage that he claims has been one that "stood in my memory all the time". Yet, the point of observation fluctuates - from Lichanec seeing his grandfather "through the window" to seeing himself from his grandfather's vantage point, "until I got out of sight". The conflicting point of production of the image represents seeing the past as an act of distancing. This is an organizing representation of his migration experience. Lichanec further recalls the event entirely in visual terms "today, at my age, I don't know why, but I could draw a picture of that man standing there, the way he was looking". This particular life history is organized in imagistic moments.

Vincent Cioffari, who immigrated in 1917 as an 11-year old, recalls a series of visual events with haptic or sound dimensions - an earthquake and iron bar reinforcements in the houses of his home town, the arrival of the first car to the town, a water fountain in the town centre and the boat carrying immigrants dodging a German torpedo on its transatlantic crossing. He describes seeing rainwater collected for washing in terms of "music" of raindrops falling on the metal pots. While the mere frequency of the sensory modalities may not be particularly insightful for analysis of differences among the senses in this corpus or to generalize migrant experience, the frequency of particular sensorial representations in individuals' ontologies point to meaningful patterns. The "interconnected and interrelated" (Pink 2012, 5) nature of sensory modalities requires the analysis to be focused on shared patterns as well as their presence in the context of individual interviews.

\section{Bullying}

Disorientation surfaces in the affective-sensory theme of bullying. The immigrants who included this experience in their life histories remembered the cruelty and negative affects. The five incidences across four interviews in the Austria-Hungary corpus respond to the interviewers' elicitations, such as "how did you learn English, did the kids at school help you?" or "did you ever hear the expression, 'greenhorn'?" and, "did kids make fun of you?" Being humiliated or ridiculed were reported by Andrew Lichanec together with strategies he used for overcoming that difference: "Oh yes, the kids always pick on you, you know, and make you a little 
uncomfortable, but after a while it, you're with them and it kind of would, you know, wear off'. Mary Thome captures her own ambivalence:

Eventually, oh, I looked so funny, too. I had different kind of clothes. I had old country clothes on, stockings with circles around them, long dress down to my ankle, and I had to wear all the, those were the only clothes I had for an awfully long time ... And, of course, the kids made fun of me because I was dressed so funny and I didn't know what was going on.

Mary Vokaty fought back: "They made fun of all the foreigners. When they came here they called us greenhorns. And, but somehow, maybe the grownups, I don't now how they took it, but I didn't". Rozia Frankel, whose entire life history prior to arrival to America was a chain of upheavals, reflects on the "unfortunate experience in school [being] the cruelty of the American children" but remembers another child, a friendly neighbor (an ally) who helped and "guided me back from school". The neighbourhood and the school provided the boundaries and surfaces for reflecting the sensory-affective experiences of these individuals. These children negotiated their own social order where they "domesticate the new spaces" in the urban territory, independently of the order of adults (Koskinen-Koivisto and Seitsonen 2019, 25). Their narratives emphasize social re-positioning linked to achieving the mastery of English and the strategies and agency that children had to demonstrate in their everyday lives in the shared experience of migration.

These incidents are multi-sensorial performances of memory. The instants mediated through sense descriptions in the constructions in the oral interviews are analogous to the "madeleine". For Marcel Proust, the construction of smell is the launching point for an inscription of memory in this instance of "Proustian" writing (Danius 2002). The imagistic moments and ocular-centric representations in the vernacular memories of the EIOH collection, similarly, are representations created through cultural repertoire drawn from an individual's sensorial affordances. The individuals' recollections emerge in relation to a shared sentiment or "structure of feeling" (Williams and Orrom, 1954) that surfaces in "aggregative" reading using a macro-approach and analyzing the corpus as well as through idiosyncratic individual performances that exemplify subjective sensory strategies and ontologies (dimensions of the "real") that organize their migration narrative.

\section{Micro-readings of individual experiences}

Two micro-readings of oral histories presented next will show how the analysis can be rooted in particular senses and how narrative choices and expressions rely on particular visual, kinaesthetic, sonic, or olfactory language representation as a surface for a shared experiential world of self and others (MacDougall 1998, 53). Storytelling draws on particular sensorial interpretations and intents preserved in the "magical moments" that summarize experiences in the life stories of these migrants. 


\section{Microreading I (acoustemology): the case of Rozia Frankel}

Rozia Frankel, a Jewish immigrant from a historical province of Galicia in AustriaHungary, remembered the exact moment when her mother decided to emigrate, which relies on a sonic sensorium. The mother is the emigrating link that structures her own migration story and the main protagonist of the magical instant at the centre of Rozia Frankel's migration experience,

Then we stayed there for a year and then someone came from the United States to visit, a couple of people that she knew, and they were talking English and mother was very much impressed with it [emphasis added]. And she left me with some family in Stryj, and the boys were taken care of through court, and she migrated to the United States in 1910 or 1911, I don't remember exactly, and I remained, but by 1913 my grandfather felt that I ought to be with my mother.

This acoustemological event is staged as a "turning point" in Frankel's migration story and gives it a fairy-tale character. There is an arbitrary and intuitive dimension to this particular event that makes it epiphanic and destinatory. Frankel's account is performed as a kinship narrative (Van Vleet 2008). Otherwise factual and wellremembered, her departure story has a nested structure in which migration involves a complex family history and exemplifies the condition of women migrants for whom America enables social restructuring. In this family legend, one overcomes social exclusion of widowhood (the mother who emigrates) and of becoming orphaned (her immigrant daughter). They can have a new life as migrants even if the story does not support re-establishment of a family home when their picaresque lives become relocated. Positioned within a migration narrative is the critique of the social order in the country of origin. The death of Rozia Frankel's father, disinheritance of her widowed mother due to religious laws in Austria-Hungary that invalidated their marriage in a synagogue, and dispersal of siblings to various relatives are central to this narrative. The act of emigration may be seen as a ritual that enables transformation (Van Gennep 1909). The epistemological goals and affects of this memory narration are organized through a sonic event, situated within a historical sensorium, and supported by sensorial language. The imagistic events that involve "an exploration of sonic sensibilities, specifically of ways in which sound is central to making sense, to knowing, to experiential truth" and suggesting that "experience of place is grounded in an acoustic dimension" (Feld and Basso 1996, 97) are also revealed in another case.

\section{Microreading II (acoustemology): the case of Marie Kovac (Di Bella)}

Marie Kovac (married Di Bella) came to America in 1913 from Rijeka, Croatia when she was six years old, adopted by her aunt after her mother's death. She was 88 years old at the time of the interview that was conducted in 1995 by NPS's Janet Levine. 
The interviewer's reliance on the interview guide systematically obstructed Marie in creating a coherent story from within her own associative links and she fends off numerous, often misleading questions by the NPS interviewer, who operated on the multiple assumptions about the immigrant's class and experience of passage. Nevertheless, Marie Di Bella (Kovac) courteously acknowledges at the conclusion of the interview, "you brought everything forth with your questions" as she apologized for her supposed lack of performance: "I am sorry I cannot contribute the right way, you mean, remembering”. In response to interviewer's question implying that she would have a sensational first impression of America on arrival ("What did you think about America?") she responds, reasonably: "How can a child think of it, I have not seen it yet, how could I think of it?" The question about her arrival to Ellis Island and what it meant to her, Marie Di Bella (Kovac) answers,

MARIE: I should remember, I do remember, but what I am trying to say is I do not remember any particular details, you know, it was evening and then of course we did not leave until morning and that was exciting, America, you know, the word alone, New York [emphasis added] ... well there is not much to tell about, I can tell nothing I can recount

INTERVIEWER: Do you have any impressions about Ellis Island coming here? MARIE: I forgot ... we were together my aunt my cousin and I, and this is very nice, decent, the people were pleasant in ... Ellis Island is a big word to Europeans, it used to be, you know, in Europe many years ago when they reached there they know that they are safe, in New York [emphasis added].

Probed on the experiences of childhood, a recurrent motif in her interview refers to music from the street in her family home in Rijeka, described as "off the main street six-room apartment, nice ... with a built in fireplace in the kitchen to cook on [that] kept you warm in the winter" and "a large wall, very pleasant wall and we played outdoors all the time". She added, "everyone went to the window to hear music; in Europe there is a lot of that". She returned two times to her hometown in 1973, after she was widowed, and again remembers acoustically,

[W] hen I made it my business to get the courage to do it alone, I went to Europe and I went to the spots that I remember with pleasure, you know, the parks, where in the evening we would hear music playing in Dalmacija, oh this I wanted to replenish my memories with the same.

The narrator repeats and comes back in semi-indulgent semi-awareness to the recurring, metonymic, and involuntary surfacing of the themes. Against the fragility of her age, Marie Di Bella (Kovac)'s disposition and mood recalled in the repetition of the word "pleasant" is supported by sensory markers: a velvet couch that she remembers from the second-class cabin that was shared with her aunt and cousin, the monumental staircases they ascended at dinner time, and a penny with an 
"Indian" figure that someone gave her on the boat. Often she would recall "pleasant" to avoid interviewers' assumptions, such as in this exchange,

MARIE: Ivernia was the ship [she spells the name] - the passage was very pleasant, it was very pleasant, we had a beautiful dining room, a beautiful staircase going to the dining room a lot of servers? It was very nice.

INTERVIEWER: [notes that she must not have been traveling steerage]

MARIE: No, no, I was with my aunt and cousin ... so that was a bedroom with two beds, one higher than the other; my aunt had a lower one and my cousin who was younger, she was there ... and I was tucked in on a velvet couch on the other wall, you know, so it was cozy.

The recurring sentiment word "pleasant" is attached to the journey, the passage through Ellis Island she could not remember, the train journey to Cleveland, growing up in the United States, and growing old.

She does insist on the relevance of songs she heard in her native Rijeka in Croatia, sung in the parks and referring to a gentile, urban culture of Austria-Hungary, which she searched for on her return visits, without success. At the end of the interview, she remembers a tune and starts singing: "Samo reci mi da te ljubim ja, to nije istina - naranana" and then continues "Ružice brala, dragom je dala - la ra la la la". Then she cries slightly, overtaken by the emotion of her sudden memory and abandoned in its sound. She immediately translates (actually, mis-translates) the words in English as if to explain her lapse to the interviewer: "Picking flowers and giving [them] to my lover". The sound of her voice singing the song comes to life as if from another register-as alive and different in the way she pronounced "Dalmacija" in fluent Croatian without any trace of an English accent, as if she bracketed her memory or as if this facility burst through in her narrative. That word is oddly different as is the song when contrasted to the spotless English of her interview. She shifts to another linguistic register. The place of her childhood, that de-Americanized onomastic, is an ontological intervention that melds temporalities. Just as Marie was about to elaborate on this memory, the NPS interviewer cut her off, then switched off the tape. One may guess that the NPS interviewer was emotionally alienated by these expressions or could not understand their relevance in Marie's migration story and how she represented time with this realtime performance of sound. The oral history interview is a representation of Marie Di Bella (Kovac)'s sensorium. The song that she is trying to remember throughout the interview stood out as a main event of that interview together with the velvet couch she recalled in the second-class cabin of the immigrant ship. The understanding of the senses is shared - by the researcher and in the voice of that "distant" participant. Her memory demonstrates how corporeal and sensory knowing is constructed and "relating ways of knowing to specific sensory modalities" and that the "sensory categories [that] are used by people in the ethnographer's own culture or to elucidate the sensorium of people in other cultures, [are] an exercise that might involve forms of comparison" (Pink 2012, 6-7). Marija Dalbello and Catherine McGowan could recognize and construct these experiences through their own distinct experiences and 
sensibilities. This interview only exists in audio and thus demonstrates how an auditory record can produce a sense of intimacy, with sounds and silences, and repetitions, distinct from a transcript.

\section{Conclusions}

The aggregative or macro- and micro-readings delineated the sensorium of migration mediated in the EIOH archive. We focused on a subset of interviews from Central and Southern Europe in order to emphasize the potential for historical ethnography using pre-elicited oral history archives. We recognized that oral history interviews were constructed texts and a medium that revealed the cultural politics of archives as exemplified by the interviewing techniques of the NPS staff. Although we recognized the ethical pitfalls of a project that relies on particular ideologies of migration thus inscribed in the archive, we also recognized that aggregative analysis could contextualize sensorial events across the corpus and provide access to a shared experience of migration and the shared structure of feeling of a historical sensorium. The systematically collected memory narrations recorded with a number of individuals have inherent potential for comparative analysis. This research has shown the potential of working with an existing corpus of pre-elicited oral histories that can be transferred to a range of community archives documenting the voices "from below" and genocide archives. We also reacted to particular life histories in a personal way that has both influenced the coding and the interpretation of individual interviews.

This project has shown that research of how sensoria are constructed is both a phenomenological and epistemological project involving sensory knowing and intertwined sensoria - of the participants and the researchers who coded and interpreted this corpus, each activating specific sensory modalities. Reading the cases through the affective-sensory lens of poignant moments that stand out in each individual narration, structuring these first-hand accounts of life narrations, is a subjective, affective, and sensory project. We claim the subjectivity of our analysis and we relied on our responses to interpret them. The historical ethnography in the archives is also an exercise of poetic interpretation by which subjective readings uncover first-person points of view and immigrants' perspectives, assuming the intentionality and directed attention of a conscious self in the context of a subject interpreting her life (Dalbello 2019). The aggregative analysis used a sensory-affective approach across the corpus. The micro-analysis has shown that the apparent serendipity of moments follows the classic phenomenological approach in which bursts of meaning reveal the sharpening of attention of the self towards objects through epiphanic instants (Kearney 2008, 38).

Outlining the sensorium of the Great Migration from Europe to America from an oral history archive shows that the analysis is steeped in affect-driven response that provides a position for the cultural analysis of migration. The critical standpoints for the political analysis of culture and the sentiments around the migration experience of the past and in the current formations of citizenship rely on the ability to address such construction and politics of the archives. 


\section{References}

Dalbello, M. 2019. "Archaeological sensations in the archives of migration and the Ellis Island sensorium". Archaeology and Information Research, a special issue of Information Research 24 (2). www.informationr.net/ir/24-2/paper817.html

Danius, S. 2002. The Senses of Modernism: Technology, Perception, and Aesthetics. Ithaca and London: Cornell University.

Feld, S., and K. H. Basso, eds. 1996. Senses of Place. Santa Fe: School of American Research Press.

Jay, M. 1994. Downcast Eyes: The Denigration of Vision in Twentieth-Century French Thought. Berkeley, CA: University of California Press.

Kearney, R. 2008. "Bachelard and the epiphanic instant". Philosophy Today (Supplement) 42: $38-45$.

Kennedy, John F. 1964. A Nation of Immigrants. New York: Popular Library.

Koskinen-Koivisto, E. and Seitsonen, O. 2019. "Landscapes of loss and destruction: Sámi elders' childhood memories of the Second World War". Ethnologia Europaea 49 (1): 24-40.

Kuusisto-Arponen, A-K. and U. Savolainen. 2016. "The interplay of memory and matter: narratives of former Finnish Karelian child evacuees”. Oral History 44 (2): 59-68.

Laakkonen, S. 2011. "Asphalt kids and the matrix city: Reminiscences of children's urban environmental history". Urban History 38 (2): 301-323.

MacDougall, D. 1998. Transcultural Cinema. Princeton, NJ: Princeton University Press.

Oral Histories, The Statue of Liberty - Ellis Island Foundation (accessed 2 December 2019).

www.libertyellisfoundation.org/oral-history-library

Vincent Cioffari, oral history interview conducted by Janet Levine, December 3, 1994, recording.

Marie Di Bella (Kovac), oral history interview conducted by Janet Levine, September 22, 1995, recording.

Rozia Frankel, oral history interview conducted by Margo Nash, September 5, 1974, interview NPS-73, transcript.

Stephen Houbrick, oral history interview conducted by Nancy Dallett, February 5, 1986, interview AKRF-136, transcript.

Andrew Lichanec, oral history interview conducted by Debby Dane, February 5, 1986, interview AKRF-170, transcript.

Mary Thome, oral history interview conducted by Nancy Dallett, November 6, 1989, interview DP-54, transcript.

Anna Vislocky, oral history interview conducted by Nancy Dallett, June 2, 1986, interview AKRF-179, transcript.

Mary Vokaty, oral history interview conducted by Andrew Phillips, March 25, 1989, interview DP-007, transcript.

Pink, S. 2012. Doing Sensory Ethnography. 2nd edn. Thousand Oaks, CA: Sage.

Povrzanović Frykman, M. 2016. "Sensitive objects of humanitarian aid corporeal memories and affective continuities". In Sensitive Objects. Affect and Material Culture, edited by J. Frykman and M. Povrzanović Frykman, 79-104. Lund: Nordic Academic Press.

Rose, G. 2016. Visual Methodologies: An Introduction to Researching with Visual Materials. 4th edn. Thousand Oaks, CA: Sage.

Van Gennep, A. 1909. Les Rites de Passage. Paris: Emile Nourry.

Van Vleet, K. E. 2008. Performing Kinship: Narrative, Gender, and the Intimacies of Power in the Andes. University of Texas Press.

Varricchio, M. 2011. "Golden door voices: Towards a critique of the Ellis Island Oral History Project". Oral History Forum d'histoire orale 31: 1-28.

Williams, R., and M. Orrom. 1954. Preface to Film. London: Film Drama. 


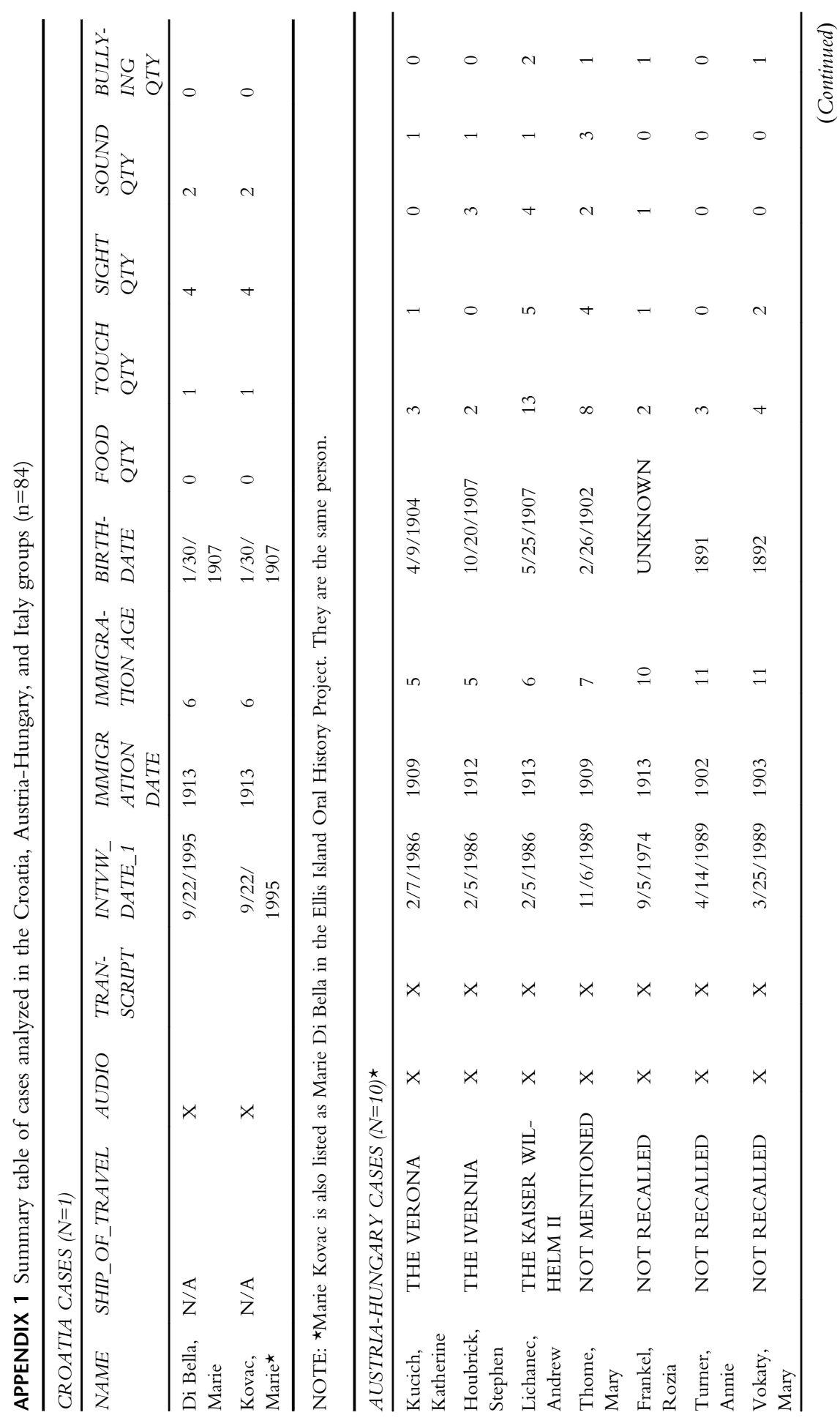




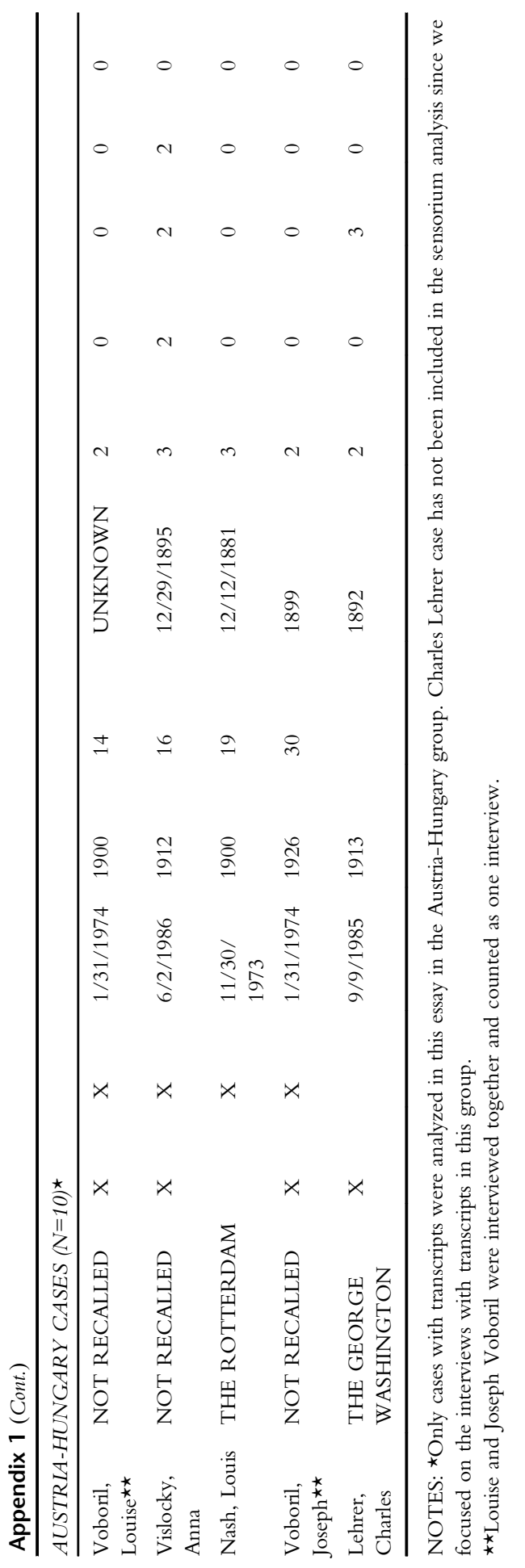




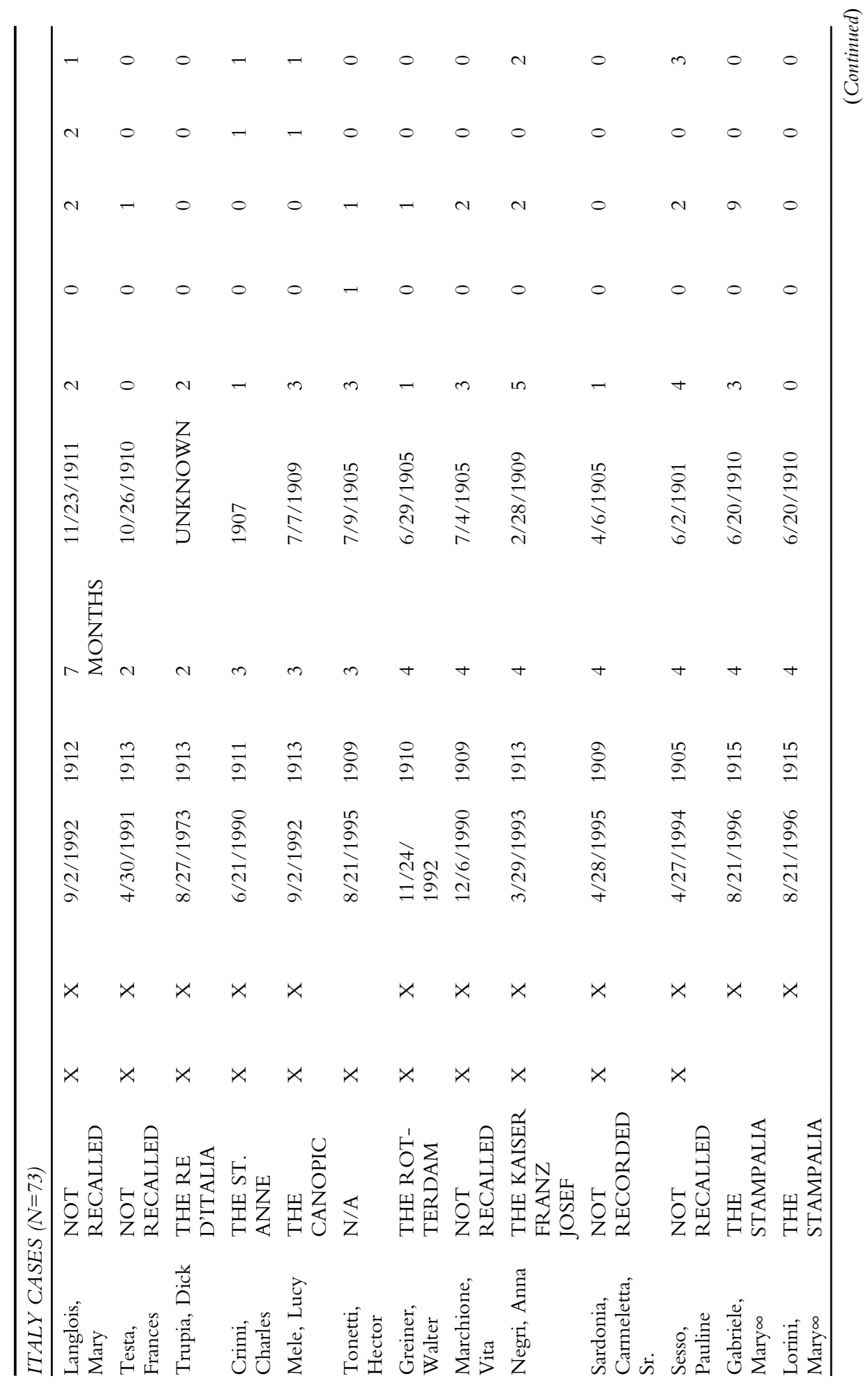




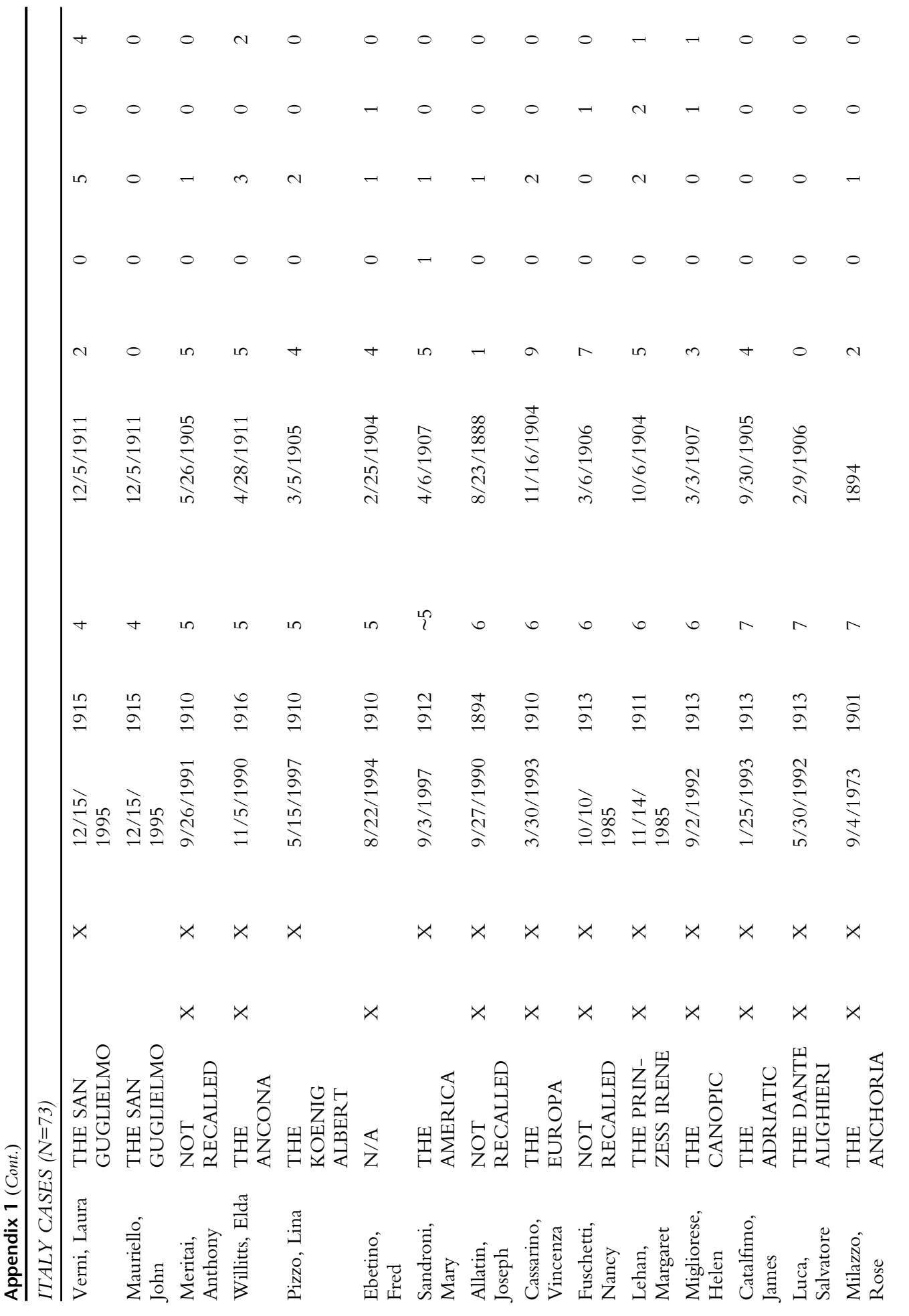




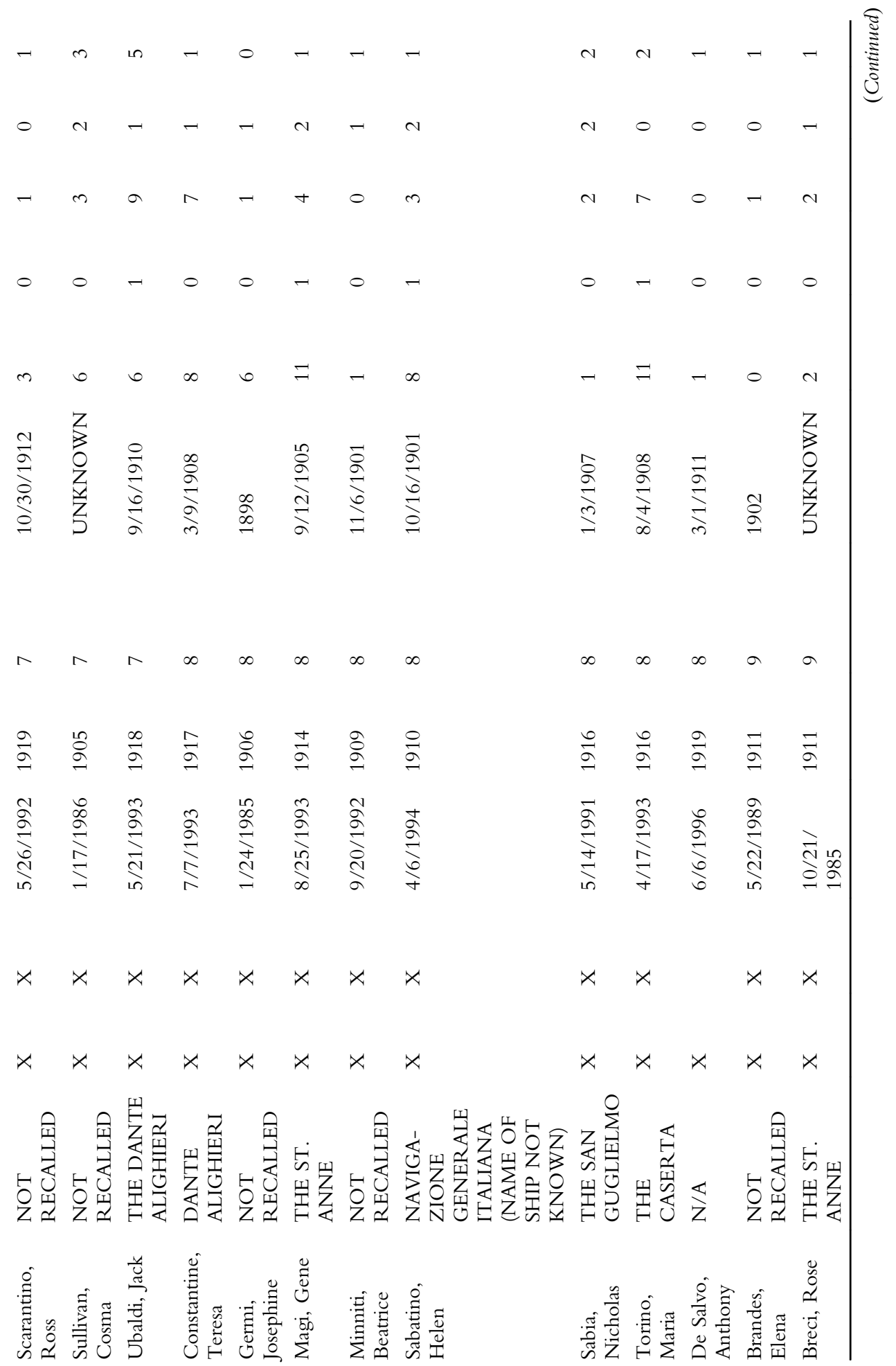




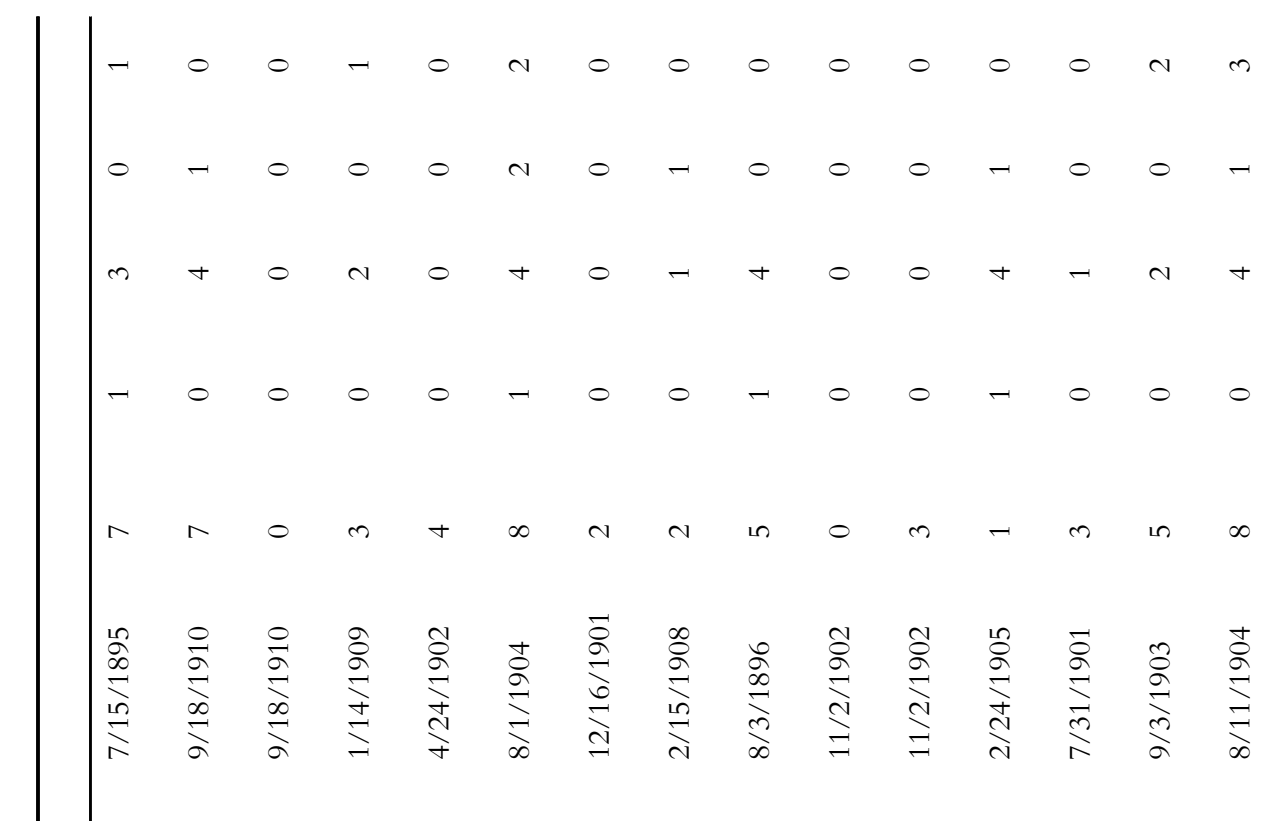

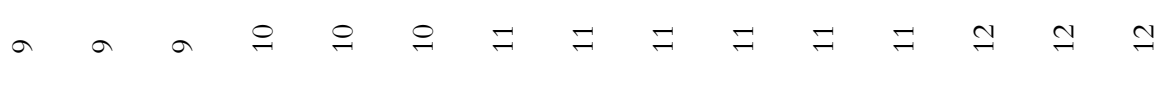

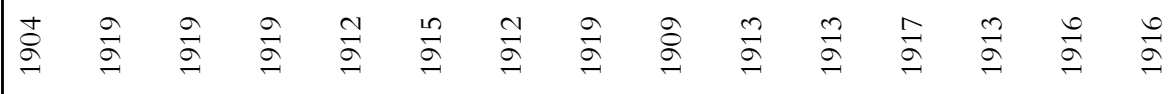

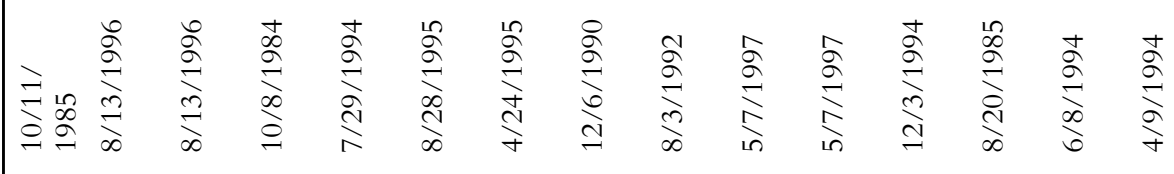

$$
\begin{aligned}
& \times \quad \times \quad \times \quad \times \quad \times \quad \times \quad \times \quad \times \quad \times \quad \times \quad \times \quad \times \quad \times \\
& x \quad x \times x \times x \times x \quad x \quad x \times x
\end{aligned}
$$

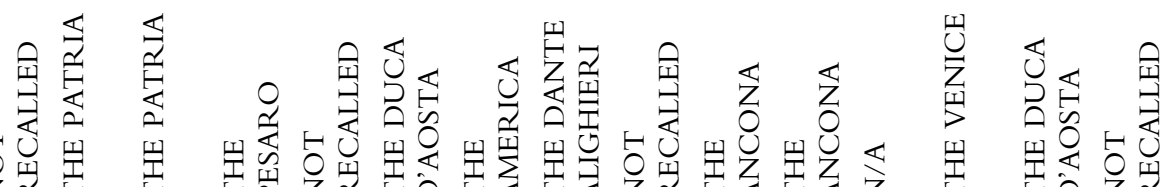

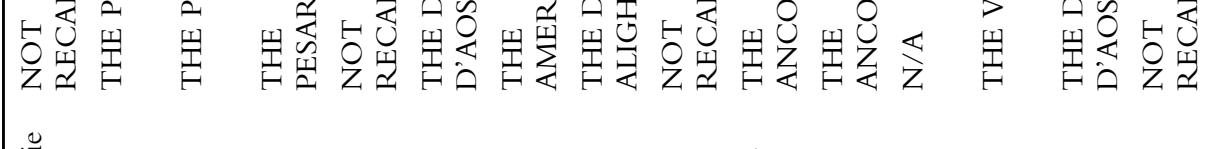




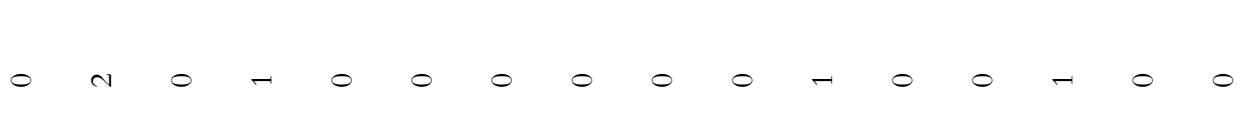

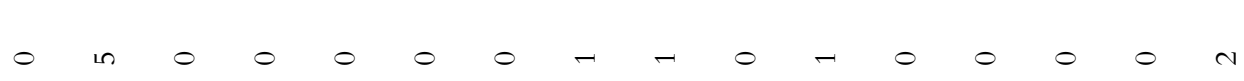

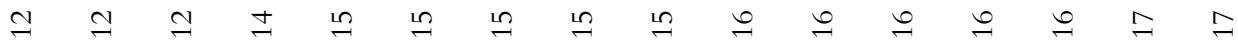

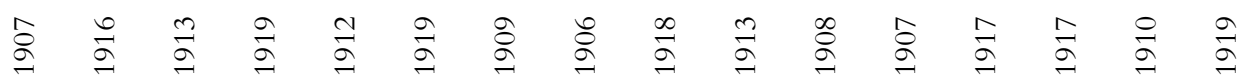


$x \quad x$ $x \times x \times x$ $x \quad x \quad x \quad x \quad x \quad x \quad x \quad x \quad x \quad x \quad x \quad x$

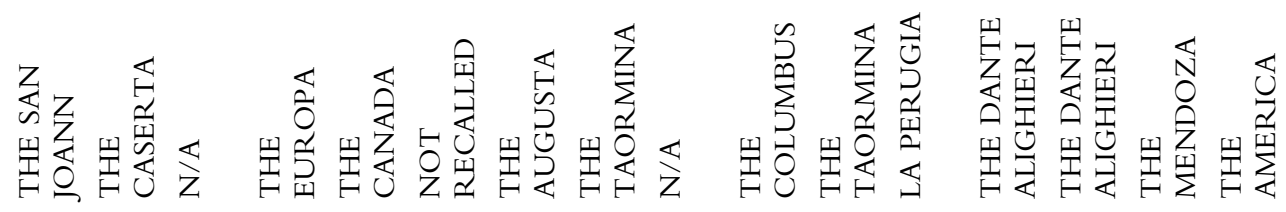

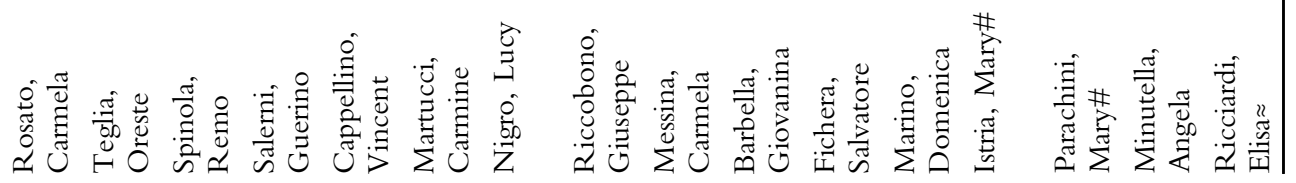




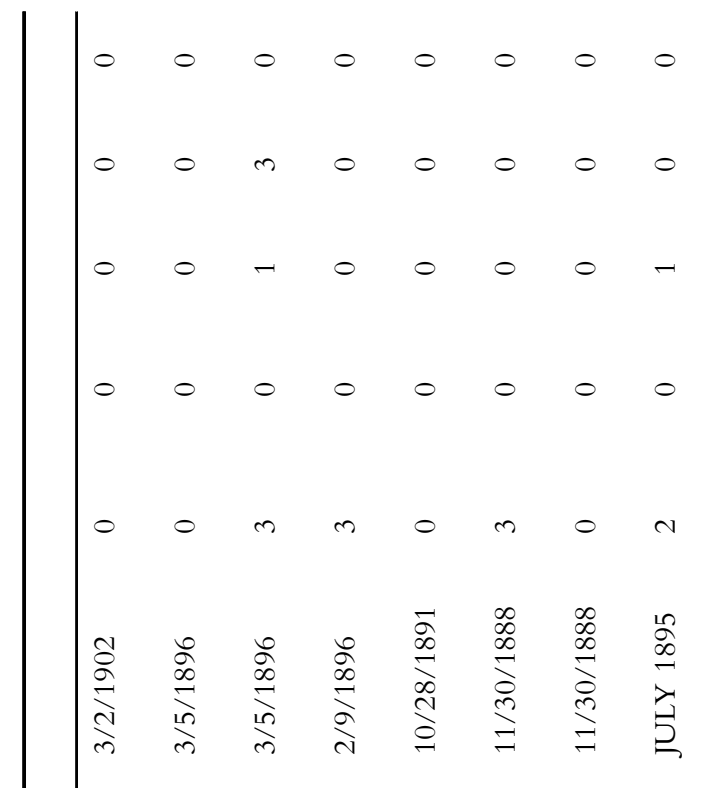

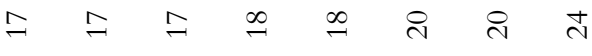

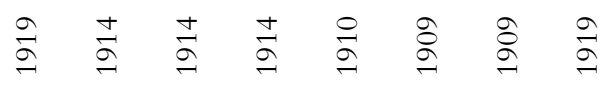

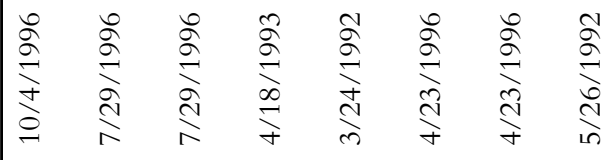

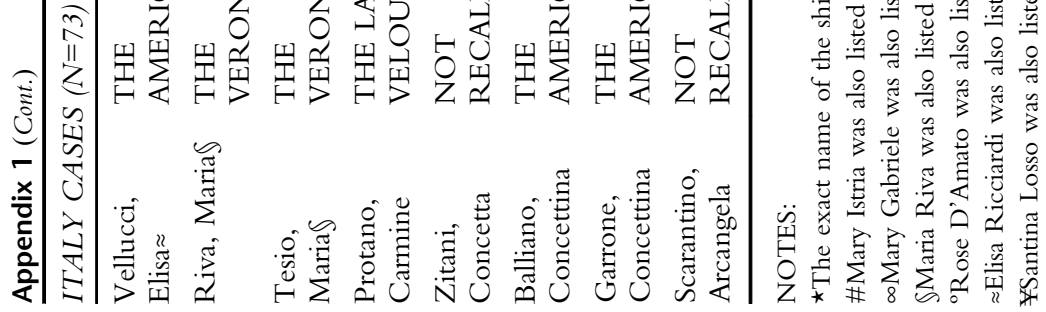

